\title{
Serum neurofilament light chain and optical coherence tomography measures in MS
}

\author{
A longitudinal study
}

\author{
Eleonora Tavazzi, MD, Dejan Jakimovski, MD, PhD, Jens Kuhle, MD, PhD, Jesper Hagemeier, PhD, \\ Osman Ozel, MD, Murali Ramanathan, PhD, Christian Barro, MD, PhD, Niels Bergsland, PhD, \\ Davorka Tomic, MD, Harald Kropshofer, MD, David Leppert, MD, Zuzanna Michalak, PhD, Norah Lincoff, MD, \\ Michael G. Dwyer, PhD, Ralph H.B. Benedict, PhD, Bianca Weinstock-Guttman, MD, and \\ Robert Zivadinov, MD, PhD
}

Neurol Neuroimmunol Neuroinflamm 2020;7:e737. doi:10.1212/NXI.0000000000000737

\author{
Correspondence \\ Dr. Zivadinov \\ rzivadinov@bnac.net
}

\section{MORE ONLINE}

$\rightarrow$ Class of Evidence

Criteria for rating

therapeutic and diagnostic studies

NPub.org/coe

\section{Methods}

In this prospective study, 110 patients with MS were recruited, together with 52 age- and sexmatched HCs. Clinical evaluation and spectral domain OCT and sNfL were obtained at baseline and after 5.5 years of follow-up. Nested linear mixed models were used to assess differences between MS vs $\mathrm{HC}$ and associations between sNfL and OCT measures. Partial correlation coefficients are reported, and $p$ values were adjusted for the false discovery rate.

\section{Results}

At baseline, peripapillary retinal nerve fiber layer thickness (pRNFLT) and macular ganglion cell and inner plexiform layer thickness (mGCIP) were significantly lower in MS than HC both in MS-associated optic neuritis (MSON) $(p=0.007, p=0.001)$ and nonaffected MSON (nMSON) eyes $(p=0.003, p=0.018)$, along with total macular volume (TMV) in $\mathrm{n}-\mathrm{MSON}$ eyes ( $p$ $=0.011)$. At follow-up, MS showed significantly lower pRNFLT, mGCIP, and TMV both in MSON and n-MSON eyes $(p<0.001)$ compared with HC. In MS n-MSON eyes, sNfL was significantly associated with baseline pRNFLT and mGCIP $(q=0.019)$. No significant associations were found in MSON eyes.

\section{Conclusions}

This study confirms the ability of sNfL to detect neurodegeneration in MS and advocates for the inclusion of sNfL and OCT measures in clinical trials.

\section{Classification of evidence}

This study provides Class III evidence that sNfL levels were associated with MS neurodegeneration measured by OCT.

\footnotetext{
From the Buffalo Neuroimaging Analysis Center (E.T., D.J., J.H., O.O., N.B., M.G.D., R.Z.), Department of Neurology, Jacobs School of Medicine and Biomedical Sciences, University at Buffalo, State University of New York; IRCCS (N.B.), Fondazione Don Carlo Gnocchi, Milan, Italy; Neurologic Clinic and Policlinic (J.K., C.B., Z.M., N.L.), Departments of Medicine, Biomedicine and Clinical Research, University Hospital Basel, University of Basel, Switzerland; Department of Pharmaceutical Sciences (M.R.), Jacobs School of Medicine and Biomedical Sciences, University at Buffalo, State University of New York; Novartis Pharma AG (D.T., H.K., D.L.), Basel, Switzerland; Jacobs MS Center (R.H.B.B., B.W.-G.), Department of Neurology, Jacobs School of Medicine and Biomedical Sciences, and Center for Biomedical Imaging at Clinical Translational Science Institute (R.Z.), University at Buffalo, State University of New York.
} 


\section{Glossary}

ART = activated real-time eye tracking; CEG-MS = cardiac, environmental, and genetic factors in MS; DMT = diseasemodifying therapy; EDSS = Expanded Disability Status Scale; ETDRS = Early Treatment Diabetic Retinopathy Study; GCIP = ganglion cell and inner plexiform layer thickness; $H C=$ healthy control; IQR = interquartile range; INL = inner nuclear layer; LMM = linear mixed model; $\mathbf{m G C I P}=$ macular GCIP; $\mathbf{m I N L}=$ macular INL; $\mathbf{n}-\mathbf{M S O N}=$ nonaffected MSON; OCT = optical coherence tomography; PMS = progressive MS; $\mathbf{p R N F L T ~ = ~ p e r i p a p i l l a r y ~ r e t i n a l ~ n e r v e ~ f i b e r ~ l a y e r ~ t h i c k n e s s ; ~ R R M S ~ = ~ r e l a p s i n g - ~}$ remitting MS; sNfL = serum neurofilament light chain; TMV = total macular volume; $\mathbf{W M}=$ white matter.

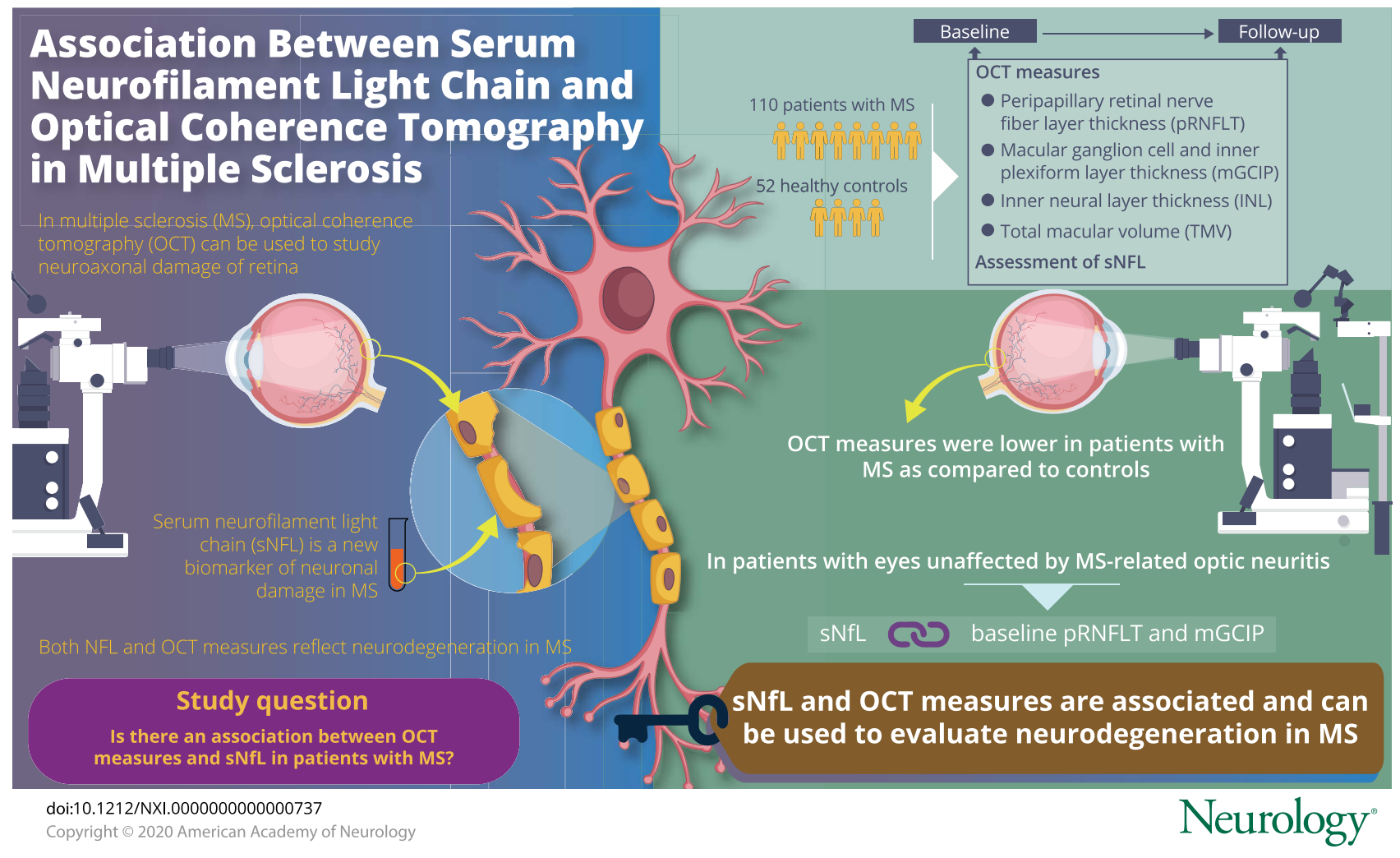

In the last decade, the development of novel paraclinical tools has remarkably expanded the knowledge on MS pathogenesis. From the traditional concept of an inflammatory white matter (WM) disease, MS is now known to be characterized by both WM and gray matter damage, with neurodegenerative mechanisms playing a key role from the onset and are predictive of long-term disability. ${ }^{1-4}$

Advanced MRI techniques have given a significant contribution in this regard, allowing, since early disease stages, the quantification of regional and global brain atrophy, the visualization of cortical lesions, and a better understanding of the interplay between inflammation and neurodegeneration within brain tissue., ${ }^{5,6}$ However, nonconventional MRI requires postprocessing experience and is usually available only in research settings. Therefore, in vivo, easily accessible biomarkers of disease progression are still lacking, and their identification is a goal of paramount importance in the MS field.

Recently, optical coherence tomography (OCT) has been applied to the study of MS, as it is a well-tolerated, inexpensive, and reproducible technique that enables the study of different retinal layers, including those where neurons and axons reside. ${ }^{7}$ A growing body of evidence supports the use of OCT measures such as peripapillary retinal nerve fiber layer thickness (pRNFLT), ganglion cell and inner plexiform layer thickness (GCIP), inner neural layer thickness (INL), and total macular volume (TMV) in the MS research setting, as they reliably reflect neuroaxonal damage. ${ }^{8-11}$ Indeed, some MRI and OCT studies have shown associations between reduced pRNFLT and GCIP with brain atrophy, supporting the role of these measures as markers of global neurodegeneration. ${ }^{12-15}$ Furthermore, pRNFLT is related to physical and functional disability, ${ }^{16,17}$ cognitive impairment, ${ }^{16}$ and clinical and MRI evidence of disease activity ${ }^{18,19}$ and is able to predict long-term disability. ${ }^{20}$ Similar associations have also been found with $\mathrm{TMV}^{21}$

Another branch of active research in the MS arena has pertained to laboratory biomarkers, with somewhat unsatisfying results due to both the inherently invasive procedure needed to obtain them (i.e., lumbar puncture) and the inability to add 
alternative information to MRI. ${ }^{22,23}$ Therefore, the identification of a biomarker whose serum levels are highly correlated with those in the CSF, namely serum neurofilament light chain (sNfL), has been greatly welcomed. ${ }^{24,25} \mathrm{NfL}$ is a subunit of the neurofilaments, scaffolding proteins abundant in neuronal and axonal cytoplasm, that are massively released in the interstitial fluid on neuroaxonal damage and circulate afterward in CSF and more recently measurable also in serum, although 40 -fold less concentrated than in CSF. ${ }^{26,27}$ Disanto et al. ${ }^{27}$ demonstrated the value of sNfL in monitoring and predicting disease evolution and response to treatment and its association with clinical and MRI markers of disease activity in 2 independent, large samples of patients with MS. Furthermore, the same group has confirmed the same results in different MS populations and found an association between sNfL and brain atrophy, confirming the usefulness of this measure as a prognostic biomarker of disease. ${ }^{28,29}$

Against this background, we planned the current study to evaluate the association between OCT measures and sNfL, as they both reflect axonal loss and neurodegeneration in MS.

\section{Methods}

\section{Subjects}

This substudy was part of a larger, 5-year prospective study on cardiac, environmental, and genetic factors in MS (CEGMS). ${ }^{30,31}$ Subjects with MS diagnosis based on the 2010 revision of $\mathrm{McDonald}$ criteria ${ }^{32}$ were recruited together with age and sex-matched healthy controls (HCs). Exclusion criteria for patients with MS applied at a subject and not eye level and were the following: idiopathic optic neuritis, optic neuritis in settings of neuromyelitis optica spectrum disorder or clinically isolated syndrome of optic neuritis, presence of relapse or steroid treatment within 30 days before the study initiation, pregnant/ nursing women, and presence of any known condition associated with brain pathology. For the current study, the sample size was determined by selecting patients and controls from the larger CEG-MS study that had SNFL and OCT measures along with an available history of MS-associated optic neuritis (MSON). Both at baseline and at follow-up visits, all the patients underwent neurologic examinations within 30 days from OCT and serum sampling, and disability was quantified by means of the Expanded Disability Status Scale (EDSS) score. The follow-up EDSS score was not validated in a subsequent visit. The history of MSON for each eye was obtained via chart review. MSON was diagnosed based on acute changes in visual acuity, accompanying symptoms of new onset of retrobulbar pain and supporting medial chart documentation. Patients with MS were classified according to disease phenotype in relapsing-remitting MS (RRMS) and progressive MS (PMS). The latter group included patients with secondary (29 patients) and primary progressive ( 7 patients) MS who were merged due to the small sample size of each subgroup. HCs were enrolled in the study if they presented with normal neurologic and agecompatible MRI examinations. A thorough description of the CEG-MS cohort has been previously described. ${ }^{33,34}$

\section{Standard protocol approvals, registrations, and patient consents}

The study was approved by the local institutional ethics review board, and all subjects provided written informed consent.

\section{OCT acquisition and analysis protocol}

OCT data are reported according to the APOSTEL guidelines. ${ }^{35}$ Spectral domain OCT (Spectralis, Heidelberg, Germany) scans were acquired both at baseline and at 5-year follow-up visits. pRNFLT was acquired with a ring type of scan, with manual placement of the ring, $768 \mathrm{~A}$-scans and circle diameter of $12.0(3.3 \mathrm{~mm})$ and activated real-time eye tracking (ART) mode set on maximum 100 frames. The optic disc was centered in all scans by an experienced technician, and scanning was performed without the use of pharmacologic dilation. When available, the follow-up images were acquired with the AutoRescan feature. On the other hand, macular GCIP (mGCIP) and macular INL (mINL) were derived by volumetric, circular, 1-mm/3-mm/6-mm Early Treatment Diabetic Retinopathy Study (ETDRS) grid, which consisted of $30^{\circ} \times 25^{\circ}$ scan area, $61 \mathrm{~B}$-scan sections with $120-\mu \mathrm{m}$ spacing, and 768 A-scans per B-scan. The center of the ETDRS grid was manually placed on the macula after activation of the ART mode on 9 frames. All layers were postprocessed and segmented on the B-scan images by the automated Heidelberg software (Spectralis Viewing Module). The mean GCIP (manual addition of the individual GC and IP layers) and INL thickness were derived. Similarly, B-scan-derived total macular volume (TMV) was calculated.

All scans were reviewed for sufficient signal strength $(\geq 20)$, correct centering, and beam placement as per the OSCAR-IB criteria. $^{36,37}$ The baseline and follow-up OCT scans were obtained using the same OCT protocol and machine that did not undergo any upgrades during the study.

\section{sNfL level analysis}

Serum samples were obtained both at baseline and follow-up during clinical examinations and properly stored. Subsequently, all serum samples from both time points were sent to the University of Basel where sNfL levels were calculated using a validated single-molecule array (Simoa) assay and quantified in picograms per milliliter, as fully described previously. ${ }^{30,31,38}$

\section{Data availability}

The data that support the findings of this study are available on a reasonable request to the corresponding author (R.Z.). The data are not publicly available due to containing information that could compromise the privacy of research participants.

\section{Statistical analysis}

All statistical analyses were performed using Statistical Package for Social Science version 24.0 (IBM, Armonk, NY). To evaluate demographic and clinical differences, the Student $t$ test, $\chi^{2}$ test, and Mann-Whitney $U$ test were used, as appropriate. Comparisons between HC and MS and RRMS and PMS were performed using linear mixed models (LMMs) with OCT as the 
Table 1 Demographic and clinical features of the study population

\begin{tabular}{|c|c|c|c|c|c|c|}
\hline & $H C(n=52)$ & MS $(n=110)$ & RRMS $(n=74)$ & PMS ( $n=36)$ & $p$ HC vs MS & $p$ RR vs PMS \\
\hline Female, $\mathrm{n}(\%)$ & $38(73.1)$ & 78 (70.9) & $57(67.0)$ & $32(76.2)$ & 0.721 & 1 \\
\hline Age, $y$ & $43.8(15.4)$ & $48.1(11.1)$ & $44.3(11.0)$ & $55.9(6.5)$ & 0.073 & $<0.001$ \\
\hline Disease duration median, y (IQR) & - & $16.5(8.7-23.0)$ & $12(6-20)$ & $21(13.5-31.5)$ & - & $<0.001$ \\
\hline EDSS score at baseline, median (IQR) & - & $2.75(1.5-5.5)$ & $2.25(1.5-3.0)$ & $5.0(3.62-6.5)$ & - & $<0.001$ \\
\hline sNfL at baseline, $\mathrm{pg} / \mathrm{mL}$ & $18.3(16.3)$ & $25.4(19.8)$ & $23.5(22.2)$ & $29.2(13.1)$ & 0.001 & 0.003 \\
\hline Relapse rate & - & $0.2(0.4)$ & $0.2(0.5)$ & $0.1(0.3)$ & - & 0.150 \\
\hline EDSS score at follow-up median (IQR) & - & $3.5(2.0-6.0)$ & $2.5(1.5-3.7)$ & $6.0(4.0-6.5)$ & - & $<0.001$ \\
\hline Absolute change EDSS & - & $0.5(0-0.5)$ & $0.5(0-0.05)$ & $0.5(0-1.0)$ & - & 0.963 \\
\hline sNfL at follow-up, $\mathrm{pg} / \mathrm{mL}$ & $20.4(20.0)$ & $27.2(18.9)$ & $22.1(13.3)$ & $37.8(24.0)$ & 0.002 & $<0.001$ \\
\hline History of ON, \% & - & $55(50)$ & $39(52.7)$ & $16(44.4)$ & - & 0.542 \\
\hline DMT, n (\%) & - & & & & - & 0.207 \\
\hline INF-beta & - & $41(37.5)$ & $28(37.8)$ & $13(36.1)$ & & \\
\hline GA & - & $23(21)$ & $13(17.6)$ & $10(27.8)$ & & \\
\hline Natalizumab & - & $18(16.4)$ & $16(21.6)$ & $2(0.5)$ & & \\
\hline Other DMT & - & $2(0.3)$ & $1(0.01)$ & $2(4.8)$ & & \\
\hline No DMT & - & $27(24.5)$ & $16(21.6)$ & $9(27.8)$ & & \\
\hline
\end{tabular}

Abbreviations: $\mathrm{DMT}=$ disease-modifying therapy; $\mathrm{EDSS}=$ Expanded Disability Status Scale; GA = glatiramer acetate; $\mathrm{HC}=$ healthy control; INF = interferon; IQR = interquartile range; PMS = progressive MS; RRMS = relapsing-remitting MS; sNfL = serum neurofilament light chain.

All metrics are reported as mean (SD) unless otherwise noted. $p$ Values were derived using the Student $t$ test, $\chi^{2}$ test, and Mann-Whitney rank-sum test, as appropriate. In bold are shown significant $p$ values $<0.05$.

response variable with random effects for subject and eye (right/left) nested within subject, to account for multiple measurements within the same individual. Models comparing RRMS and PMS were adjusted for age. As sNfL distribution was skewed, we applied a log transformation of the variable to be used in all the statistical tests. The associations between sNfL at baseline and OCT measures were investigated using LMMs adjusted for age and sex, also taking into account the interdependence of the left and right eyes. Correlation coefficients are reported. All analyses were preplanned, and all results are reported within the article. All analyses were corrected for the false discovery rate using the Benjamini-Hochberg method. Corrected $p$ values $<0.05$ (i.e., $q$ values) and original $p$ values $<0.05$ were considered significant and trend, respectively.

\section{Evaluated outcomes}

The outcome evaluated in the current study was the association between sNfL and OCT measures in HCs and patients with MS divided into 2 subgroups according to the clinical phenotype. According to the classification of evidence, the abovementioned research question showcases Class III evidence.

\section{Results}

One-hundred and ten patients with MS (74 RRMS and 36 PMS) and 52 age- and sex-matched HCs were recruited in the study. The mean follow-up period was 5.5 years (interquartile range [IQR] 5.11-5.75 years). Demographic and clinical characteristics of the study population are shown in table 1 . PMS had a significantly longer disease duration and higher EDSS than RRMS $(p<0.001)$. sNfL levels were significantly higher in patients with MS than in HCs both at baseline ( $p=$ $0.001)$ and at follow-up $(p=0.002)$, as well as in PMS with respect to RRMS, both at baseline $(p=0.003)$ and at follow-up $(p<0.001)$. In patients with PMS, $\mathrm{sNfL}$ was significantly higher at follow-up than at baseline $(p=0.006)$, whereas in HCs, patients with RRMS, and in the MS group as a whole did not significantly change over the course of the follow-up.

Some OCT data were missing, particularly from the baseline acquisitions, due to the insufficient quality of the images (68.5\%) or the presence of corrupted data that prevented analysis (31.5\%). There were no significant differences between any of the groups with respect to the participants who had available OCT measures compared with those who did not (data not shown).

\section{Healthy control vs MS}

Fifty-two patients with MS (40 RRMS and 12 PMS) experienced at least 1 episode of MSON in their lifetime. Among them, 10 patients (19.2\%) presented with MSON during the study period (median time interval between MSON and follow-up OCT 2.7 years, IQR 1.3-4.2 years), whereas the 
Table 2 Baseline OCT measures in the study population (data are reported for each eye cumulatively)

\begin{tabular}{|c|c|c|c|c|c|c|c|c|c|c|c|}
\hline & \multirow[b]{2}{*}{ HC } & \multicolumn{2}{|l|}{ MS } & \multirow{2}{*}{$\frac{\text { HC vs MS ON }}{p \text { Value }}$} & \multirow{2}{*}{$\begin{array}{l}\text { HC vs MS } \\
\mathrm{n}-\mathrm{ON} \\
p \text { Value }\end{array}$} & \multicolumn{2}{|l|}{ RRMS } & \multicolumn{2}{|l|}{ PMS } & \multirow{2}{*}{$\begin{array}{l}\text { RR vs } \\
\text { PMS ON } \\
p \text { Value }\end{array}$} & \multirow{2}{*}{$\begin{array}{l}\text { RR vs } \\
\text { PMS n-ON } \\
p \text { Value }\end{array}$} \\
\hline & & ON & n-ON & & & ON & $n-O N$ & ON & $n-O N$ & & \\
\hline PRNFLT, $\mu \mathrm{m}$ & $97.8(11.4) n=26$ & $85.4(14.2) n=54$ & $85.1(13.7) n=106$ & 0.037 & 0.024 & $87.2(13.4) n=39$ & $86.8(13.5) n=68$ & $80.8(15.5) n=15$ & $82.0(13.7) n=38$ & 0.754 & 0.559 \\
\hline mGCIP, $\mu \mathrm{m}$ & $85.2(8.5) n=24$ & $70.6(14.6) n=38$ & $75.2(13.3) n=76$ & 0.016 & 0.049 & $73.0(14.1) n=28$ & $77.9(11.5) n=51$ & $64.0(14.4) n=10$ & $69.7(15.1) n=25$ & 0.754 & 0.069 \\
\hline $\mathrm{mINL}, \mu \mathrm{m}$ & $38.1(4.7) n=24$ & $36.8(3.5) n=38$ & $37.9(3.1) n=76$ & 0.554 & 0.754 & $36.1(2.9) n=28$ & $37.5(2.9) n=51$ & $38.9(4.2) n=10$ & $38.6(3.3) n=25$ & 0.049 & 0.380 \\
\hline TMV, $\mathrm{mm}^{3}$ & $8.4(1.5) n=27$ & $7.8(0.8) n=51$ & $7.9(0.9) n=99$ & 0.554 & 0.044 & $7.9(0.8) n=37$ & $8.0(0.8) n=64$ & $7.7(0.7) n=14$ & $7.6(0.9) n=35$ & 0.754 & 0.453 \\
\hline
\end{tabular}

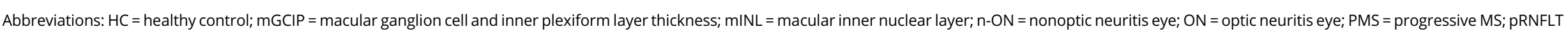
$=$ peripapillary retinal nerve fiber layer thickness; RRMS = relapsing-remitting MS; TMV = total macular volume.

( rate-corrected $p$ values [i.e., $q$ values]). In bold are shown $q$ values $<0.05$, whereas original $p$ values $<0.05$ not surviving the false discovery rate correction are shown in italics.

Table 3 Follow-up OCT measures in the study population (data are reported for each eye cumulatively)

\begin{tabular}{|c|c|c|c|c|c|c|c|c|c|c|c|}
\hline & \multirow[b]{2}{*}{ HC } & \multicolumn{2}{|l|}{ MS } & \multirow{2}{*}{$\frac{\text { HC vs MS ON }}{p \text { Value }}$} & \multirow{2}{*}{$\begin{array}{l}\text { HC vs MS } \\
\text { n-ON } \\
p \text { Value }\end{array}$} & \multicolumn{2}{|l|}{ RRMS } & \multicolumn{2}{|l|}{ PMS } & \multirow{2}{*}{$\begin{array}{l}\text { RR vs } \\
\text { PMS ON } \\
p \text { Value }\end{array}$} & \multirow{2}{*}{$\begin{array}{l}\text { RR vs PMS } \\
\text { n-ON } \\
p \text { Value }\end{array}$} \\
\hline & & ON & $\mathrm{n}-\mathrm{ON}$ & & & ON & $n-O N$ & ON & $\mathrm{n}-\mathrm{ON}$ & & \\
\hline pRNFLT, $\mu \mathrm{m}$ & $96.0(12.6) n=97$ & $81.1(15.1) n=60$ & $82.2(13.9) n=142$ & 0.003 & 0.003 & $84.1(14.7) n=44$ & $85.2(12.6) n=89$ & $72.7(13.2) n=16$ & $77.3(14.6) n=53$ & 0.861 & 0.084 \\
\hline $\mathrm{mGCIP}, \mu \mathrm{m}$ & $79.4(14.0) n=95$ & $70.7(12.9) n=58$ & $75.3(12.6) n=137$ & 0.003 & 0.003 & $70.9(12.4) n=44$ & $76.3(11.6) n=88$ & $69.9(14.8) n=14$ & $73.5(14.1) n=49$ & 0.341 & 0.330 \\
\hline $\mathrm{mINL}, \mu \mathrm{m}$ & $38.0(3.1) n=95$ & $37.8(3.1) n=58$ & $37.3(3.3) n=137$ & 0.738 & 0.210 & $37.6(2.9) n=44$ & $36.9(3.6) n=88$ & $38.5(3.6) n=14$ & $37.9(2.8) n=49$ & 0.738 & 0.084 \\
\hline TMV, $\mathrm{mm}^{3}$ & $8.5(0.6) n=95$ & $8.0(0.4) n=62$ & $8.1(0.8) n=141$ & 0.003 & 0.003 & $8.1(0.4) n=46$ & $8.2(0.4) n=89$ & $7.7(0.4) n=16$ & $8.0(1.2) n=52$ & 0.672 & 0.216 \\
\hline
\end{tabular}

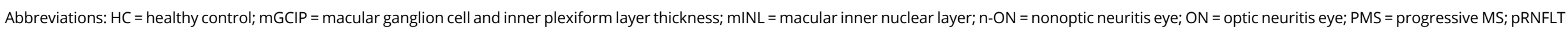
= peripapillary retinal nerve fiber layer thickness; RRMS = relapsing-remitting MS; TMV = total macular volume.

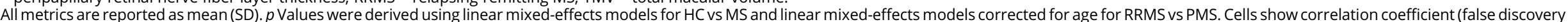
rate-corrected $p$ values [i.e., $q$ values]). In bold are shown $q$ values $<0.05$, whereas original $p$ values $<0.05$ not surviving the false discovery rate correction are shown in italics. 
Table 4 Partial correlations between baseline SNfL and OCT measures at baseline and follow-up

\begin{tabular}{|c|c|c|c|c|c|c|c|}
\hline & \multirow{2}{*}{$\frac{\mathrm{HC}}{\mathrm{n}-\mathrm{ON}}$} & \multicolumn{2}{|l|}{ MS } & \multicolumn{2}{|l|}{ RRMS } & \multicolumn{2}{|l|}{ PMS } \\
\hline & & ON & n-ON & ON & n-ON & ON & n-ON \\
\hline \multicolumn{8}{|c|}{ Baseline OCT measures } \\
\hline PRNFLT, $\mu \mathrm{m}$ & $-0.340(0.643) n=26$ & $-0.196(0.674) n=54$ & $-0.450(\mathbf{0 . 0 1 9}) n=106$ & $-0.447(0.459) n=39$ & $-0.489(\mathbf{0 . 0 1 9}) n=68$ & $0.259(0.855) n=15$ & $-0.271(0.632) n=38$ \\
\hline $\mathrm{mGCIP}, \mu \mathrm{m}$ & $-0.368(0.632) n=24$ & $-0.259(0.632) n=38$ & $-0.511(\mathbf{0 . 0 1 9}) n=76$ & $-0.389(0.960) n=28$ & $-0.540(\mathbf{0 . 0 2 8}) n=51$ & $0.129(0.855) n=10$ & $-0.386(0.192) n=25$ \\
\hline $\mathrm{mINL}, \mu \mathrm{m}$ & $0.030(0.960) n=24$ & $0.259(0.497) n=38$ & $0.111(0.702) n=76$ & $0.079(0.799) n=28$ & $0.039(0.960) n=51$ & $0.369(0.674) n=10$ & $0.255(0.478) n=25$ \\
\hline TMV, $\mathrm{mm}^{3}$ & $-0.020(0.883) n=25$ & $-0.240(0.772) n=51$ & $-0.411(0.056) n=99$ & $-0.422(0.478) n=37$ & $-0.298(0.459) n=64$ & $0.390(0.674) n=14$ & $-0.443(0.478) n=35$ \\
\hline \multicolumn{8}{|l|}{$\begin{array}{l}\text { Follow-up OCT } \\
\text { measures }\end{array}$} \\
\hline PRNFLT, $\mu \mathrm{m}$ & $-0.218(0.478) n=97$ & $-0.070(0.883) n=60$ & $-0.272(0.130) n=142$ & $-0.047(0.940) n=44$ & $-0.136(0.674) n=89$ & $-0.099(0.835) n=16$ & $-0.216(0.643) n=53$ \\
\hline $\mathrm{mGCIP}, \mu \mathrm{m}$ & $-0.068(0.751) n=95$ & $-0.177(0.563) n=58$ & $-0.076(0.673) n=137$ & $-0.219(0.478) n=44$ & $-0.066(0.799) n=88$ & $-0.135(0.809) n=14$ & $-0.015(0.883) n=49$ \\
\hline $\mathrm{mINL}, \mu \mathrm{m}$ & $0.028(0.883) n=95$ & $0.006(0.674) n=58$ & $0.067(0.960) n=137$ & $-0.065(0.883) n=44$ & $0.021(0.883) n=88$ & $0.245(0.799) n=14$ & $0.118(0.674) n=49$ \\
\hline TMV, $\mathrm{mm}^{3}$ & $0.167(0.674) n=95$ & $-0.108(0.799) n=62$ & $-0.162(0.434) n=141$ & $-0.182(0.674) n=46$ & $-0.169(0.632) n=89$ & $0.277(0.674) n=16$ & $-0.152(674) n=52$ \\
\hline
\end{tabular}

Abbreviations: $\mathrm{HC}=$ healthy control; $\mathrm{mGCIP}=$ macular ganglion cell and inner plexiform layer thickness; $\mathrm{mINL}=\mathrm{macular}$ inner nuclear layer; $\mathrm{n}-\mathrm{ON}=$ nonoptic neuritis eye; ON = optic neuritis eye; PMS = progressive MS; pRNFLT = peripapillary retinal nerve fiber layer thickness; RRMS = relapsing-remitting MS; TMV = total macular volume.

Partial correlations coefficients corrected for age and sex are shown by eyes and were derived from linear mixed models to account for the interdependence of left and right eyes. Cells show correlation coefficient (false discovery rate-corrected $p$ values [i.e., $q$ values]). In bold are shown $q$ values $<0.05$, whereas original $p$ values $<0.05$ not surviving the false discovery rate correction are shown in italics.

remaining 42 had MSON before the recruitment of the study, with a median time interval of 9.6 years (IQR 4.4-23.0 years).

Baseline and follow-up OCT measures were compared between $\mathrm{HC}$ and MS where MSON-affected and unaffected eyes (n-MSON) were ascertained, as shown in tables 2 and 3, respectively. At baseline, pRNFLT was significantly lower in MS than in HC, both for MSON and n-MSON eyes $(q=0.037$ and $q=0.024$, respectively). Moreover, mGCIP was significantly lower in MS than in HC, regardless of the presence of MSON history $(q=0.016$ for MSON and $q=0.049$ for $\mathrm{n}-\mathrm{MSON})$. Finally, TMV was significantly lower only in n-MSON eyes ( $p$ $=0.044)$ of patients with MS than in HCs.

At follow-up, MS showed significantly lower pRNFLT, mGCIP, and TMV, regardless of the presence of MSON history $(p=0.003)$. The rate of change over the follow-up did not differ between HCs and patients with MS for any of the measures, regardless of the MSON status (figure e-1, links.lww. com/NXI/A247).

Partial correlations between baseline sNfL and both baseline and follow-up OCT measures are presented in table 4. No significant associations between sNfL and any of the investigated OCT measures were found, neither in $\mathrm{HC}$ nor in MSON eyes. In n-MSON eyes, sNfL was significantly associated, at baseline, with pRNFLT $(r=-0.450, q=0.019)$, $\operatorname{mGCIP}(r=-0.511, q=0.019)$ and a trend was found for TMV $(r=-0.411, p=0.005, q=0.056)$, and with pRNFLT at followup $(r=-0.272, p=0.014, q=0.130)$ as shown in figure 1 . No associations were found between baseline sNfL and OCT changes over time for any of the investigated measures.

\section{Relapsing-remitting vs progressive MS}

Tables 2 and 3 show the baseline and follow-up OCT measures in MSON and n-MSON eyes, respectively, between RRMS vs PMS. At baseline, in the comparison between RRMS vs PMS, the only OCT measures significantly different were mGCIP, which showed a trend for being significantly lower in n-MSON eyes of patients with PMS ( $p=0.030, q=0.069)$ and mINL, which was significantly lower in MSON eyes of patients with RRMS than in patients with PMS $(q=0.049)$. At follow-up, no significant differences were found between MSON eyes in the 2 study groups, whereas pRNFLT showed a trend for being significantly lower $(p=0.039, q=0.084)$ and mINL showed a trend for being significantly higher $(p=0.042, q=0.084)$ in PMS MSON eyes than in RR n-MSON eyes. The rate of change over the follow-up did not differ between patients with RRMS and PMS for any of the measures, regardless of the MSON status. Changes in OCT measures over the follow-up were not significantly different between the 2 groups.

Partial correlations between baseline sNfL and both baseline and follow-up OCT measures are presented in table 4. At baseline, in RRMS MSON eyes, sNfL was not significantly associated with any of the investigated OCT measures. For RR $\mathrm{n}-\mathrm{MSON}$ eyes at baseline, sNfL was associated with pRNFLT $(r=-0.489, q=0.019)$ and $\mathrm{mGCIP}(r=-0.540, q=0.028)$, as shown in figure 1. At baseline, sNfL in the PMS group showed a trend with mGCIP $(r=-0.386, p=0.024, q=0.192)$ in $\mathrm{n}$-MSON eyes. There were no associations between baseline sNFL and follow-up OCT measures in neither the RRMS nor PMS groups. No associations were found between baseline sNfL and OCT changes over time for any of the investigated OCT measures. 
Figure 1 Scatterplots showing the association between serum neurofilament light chain (SNfL) and peripapillary retinal nerve fiber layer thickness (pRNFLT) in nonoptic neuritis ( $n-O N$ ) (A) eyes (top left) and in (C) relapsing-remitting MS (RRMS) n-ON (bottom left), and the association between sNfL and macular ganglion cell and inner plexiform layer thickness (mGCIP), in (B) MS n-ON eyes (top right), and in (D) RRMS n-ON (bottom right)
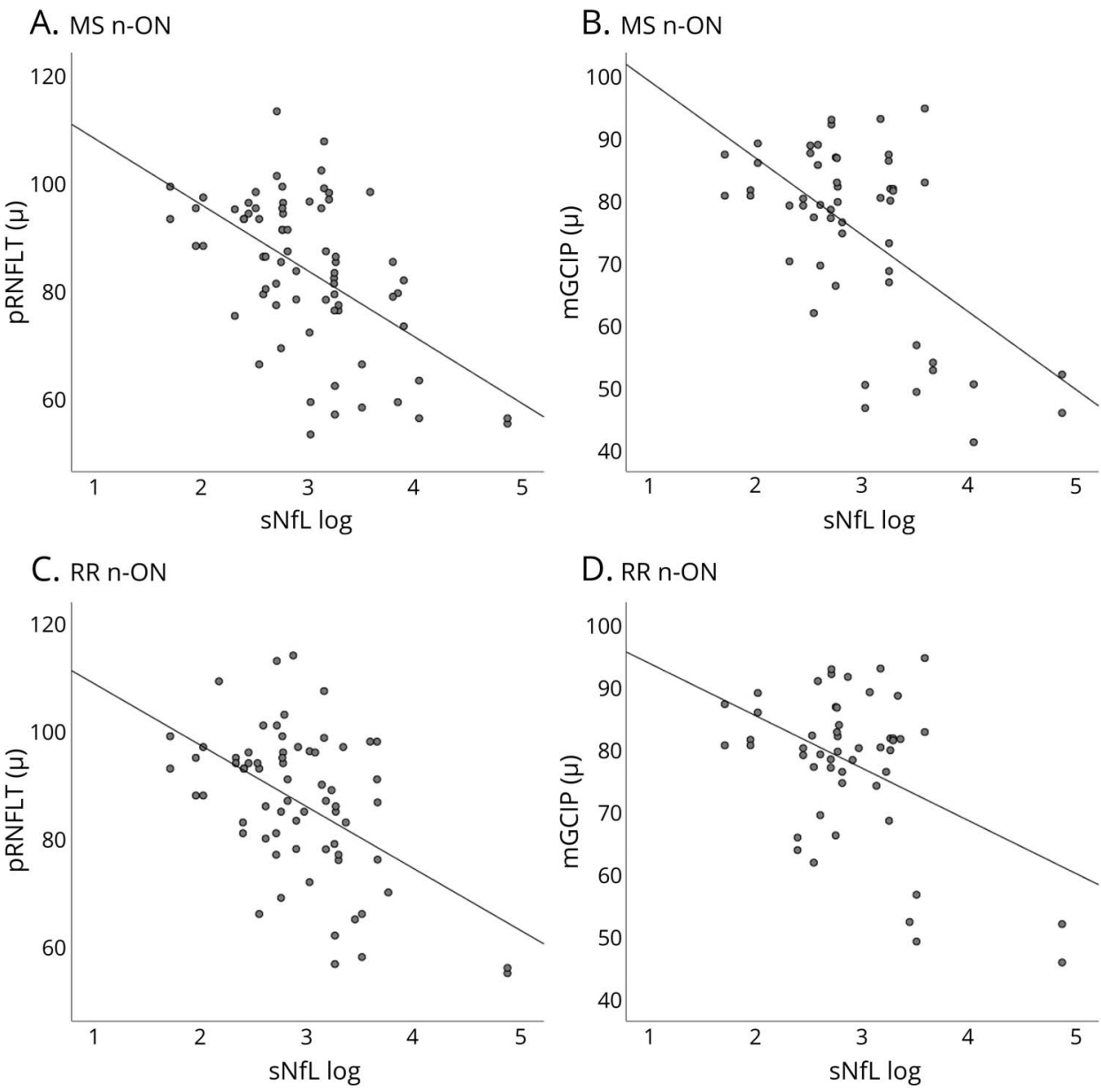

D. RR n-ON

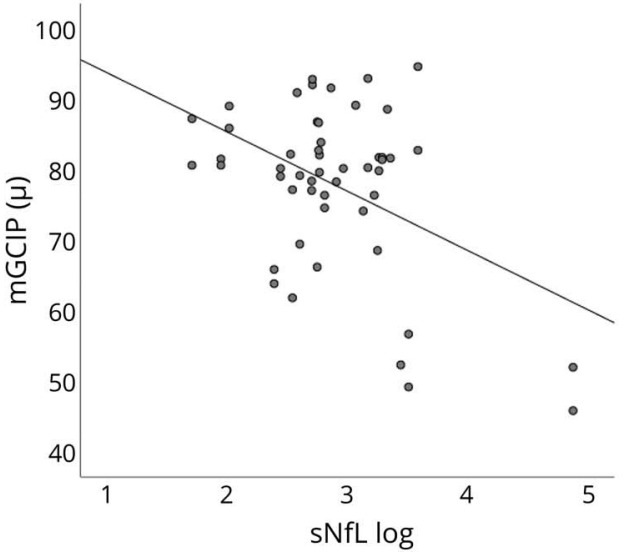

\section{Discussion}

SNfL and OCT measures have been demonstrated to be markers of neurodegeneration in MS, ${ }^{7,9,27-29}$ but the relationship between them has been scarcely investigated. ${ }^{39}$ This study shows a significant association between sNfL, pRNFLT, mGCIP, and TMV in the eyes unaffected by ON of patients with MS. Whereas sNfL has been related to both MS-related inflammation and neurodegeneration, as it increases after acute relapses but also during disease progression, ${ }^{27-29}$ the aforementioned OCT parameters seem to primarily reflect the neurodegenerative aspects of the disease. ${ }^{8}$ Indeed, pRNFLT reduction indicates axonal damage, whereas both GCIP and macula are retinal areas dense with neurons and their decrease in patients with MS, regardless of the presence of MSON history, suggests, respectively, dendrite/synapsis pruning following soma shrinkage and neuronal loss. Multiple studies have assessed sNfL in relation to both gray matter atrophy and cognitive status. ${ }^{28,30,31}$ OCT has also been found to reflect brain tissue loss. ${ }^{12,14}$ However, the direct relationship between sNfL and OCT parameters has been reported in only one study, to our knowledge. ${ }^{39}$ Specifically, Bsteh et al..$^{39}$ detected an association between increased sNfL levels and annualized RNFL loss in a group of 80 patients with RRMS without MSON history and demonstrated that sNfL could predict $15 \%-20 \%$ of the RNFL thinning variance. Our study builds on these findings, demonstrating an association with other OCT measures in both RRMS and PMS, thus supporting their role as biomarkers of neurodegeneration in MS. Indeed, being noninvasive measures, they are more easily obtainable and considerably less expensive than other paraclinical outcomes currently in use, while still having reliability and capability of providing reproducible measures of neuroaxonal damage in MS.

Perhaps surprisingly, sNfL was not related to OCT measures in the eyes affected by MSON. Furthermore, restricting correlation analyses to more informative patients with substantial sNfL change over the course of the study (as post hoc analysis, participants > median sNfL change) yielded similar results: 
sNfL was not related to OCT measures in the eyes affected by ON.

The lower sample size of affected eyes, however, is unlikely to be the sole cause of this seemingly unintuitive finding. The magnitude of the correlations was roughly half for these measures compared with those in unaffected eyes. Instead, it is likely that the focal damage caused by MSON results in the OCT-derived measures no longer being reflective of global neurodegenerative status and thus the association with sNfL resulting considerably weaker, or possibly a floor effect. This hypothesis is supported by significantly reduced RNFL and TMV in eyes affected by MSON compared with unaffected eyes (results not shown). The presence of MSON was also showed to disrupt the correlation between OCT measures and gray matter volume, confirming the potential interfering effect of focal axonal loss in the optic nerve on the relationship between brain and retinal neurodegeneration. ${ }^{40}$

Moreover, we did not detect any associations between baseline sNfL and OCT changes over time, nor any differences in OCT measures between the 2 time points (results not shown). However, we were likely underpowered to detect such changes, given the relatively small sample size of our cohort. Future studies with larger sample sizes are warranted to confirm or refute these findings.

We also repeated our analysis in different disease phenotypes. Although the findings in RRMS were largely coherent with those obtained in the entire MS sample, we disappointingly only found a single association between sNfL and mGCIP in the PMS group. We were likely underpowered in this regard as well; therefore, larger studies will be needed to elucidate this question.

Both sNfL and pRNFLT, mGCIP, and TMV were significantly altered in patients with MS at baseline and follow-up compared with HCs. Moreover, sNfL was significantly higher in patients with PMS. These findings confirm previous results supporting the role of these measures as markers of global neurodegeneration..$^{10,12,13,27,28}$ Notably, OCT measures were significantly lower also in subjects with MS without a history of MSON, reinforcing the notion that retinal damage occurs partly independently from acute inflammatory attacks of the optic nerve. ${ }^{19,41}$ These results might be justified by the presence of subclinical MSON episodes ${ }^{42}$ and by a phenomenon of retrograde degeneration derived from inflammatory episodes occurring within the optic nerve or along the optic pathways. ${ }^{43}$ It needs also to be taken into consideration, as suggested by recent studies, that a degenerative process directly affecting the retina might occur, resulting in primary retinal pathology, ${ }^{12,44-46}$ as confirmed by histopathologic data. ${ }^{47}$

A surprising finding was the INL thickening in PMS compared with RRMS in MSON-affected eyes, which might have been influenced by the small sample size. However, increased INL thickness has been observed in the context of active retinal inflammation in subjects with MS, as INL contains the highest amount of retinal glial cells. It has also been demonstrated that retinal inflammatory activity persists for months after acute $\mathrm{MSON}^{44}$ and is present also in late disease stage, ${ }^{47}$ which might support our findings. Moreover, INL thickening has been related to the presence of microcystic macular edema, a relatively uncommon phenomenon occurring in MS, related to the disruption of the blood-retinal barrier and associated with higher clinical disability. ${ }^{48}$ Unfortunately, information in this regard is not available in our patients, but this phenomenon could still be taken into account as a possible complementary explanation.

This study has limits that warrant discussion. First, the relatively low sample size, in particular with respect to MSON-affected eyes, has likely prevented us from detecting both significant differences of OCT measures in RRMS vs PMS, reported in previous studies, ${ }^{45}$ and possible associations between $\mathrm{sNfL}$ and OCT measures in PMS. The same limit might have accounted for the inability to demonstrate a possible predictive value for sNfL in terms of OCT-derived measures at follow-up except for pRNFLT in the nonaffected eyes when considering the MS sample as a whole. Larger studies are needed to overcome these issues. Second, information regarding visual acuity and color vision was not available, which might have given a more exhaustive clinical picture of the study subjects, especially with respect to residual visual disability after ON. However, the primary aim of this study was not to investigate OCT measures or sNfL with respect to visual function but to characterize their relationship in MS.

In conclusion, our study further confirms the ability of sNfL to detect neuroaxonal damage in MS and advocates for the inclusion of $\mathrm{sNfL}$ and $\mathrm{OCT}$ measures in future clinical trials.

\section{Study funding}

This study was in part funded by Novartis Pharma AG, Basel, Switzerland, and by the Swiss National Research Foundation (320030_160221).

\section{Disclosure}

E. Tavazzi and D. Jakimovski have nothing to disclose. J. Kuhle received speaker fees, research support, travel support, and/or served on advisory boards of ECTRIMS, Swiss MS Society, Swiss National Research Foundation (320030_160221), University of Basel, Bayer, Biogen, Genzyme, Merck, Novartis, Protagen AG, Roche, and Teva. J. Hagemeier and O. Ozel have nothing to disclose. M. Ramanathan received research funding or consulting fees from the National Multiple Sclerosis Society, the Department of Defense, the NIH, National Science Foundation, and Otsuka Pharmaceutical Development. C. Barro received conference travel grant from Teva and Novartis. N. Bergsland has nothing to disclose. D. Tomic, H. Kropshofer, and D. Leppert are employees of Novartis Pharma AG, Basel, Switzerland. Z. Michalak has nothing to disclose. M.G. Dwyer has received consultant fees from Claret Medical and EMD Serono. N. Lincoff has nothing to disclose. R.H.B. Benedict received personal compensation from NeuroCog Trials, 
Genentech, Roche, Takeda, AbbVie, Novartis, Sanofi, and EMD Serono for speaking and consultant fees; he received financial support for research activities from Genzyme, Biogen, and Mallinckrodt. B. Weinstock-Guttman received honoraria as a speaker and as a consultant for Biogen Idec, EMD Serono, Genentech, Novartis, and Mallinckrodt and received research funds from Biogen Idec, Genentech, EMD Serono, and Novartis. R. Zivadinov received personal compensation from EMD Serono, Genzyme-Sanofi, Celgene, and Novartis for speaking and consultant fees; he received financial support for research activities from Genzyme-Sanofi, Novartis, Celgene, Mapi Pharma, and Protembis. Go to Neurology.org/NN for full disclosures.

\section{Publication history}

Received by Neurology: Neuroimmunology \& Neuroinflammation November 5, 2019. Accepted in final form April 9, 2020.

Appendix Authors

\begin{tabular}{|c|c|c|}
\hline Name & Location & Contribution \\
\hline $\begin{array}{l}\text { Eleonora } \\
\text { Tavazzi, MD }\end{array}$ & $\begin{array}{l}\text { Buffalo Neuroimaging } \\
\text { Analysis Center, Buffalo, } \\
\text { NY }\end{array}$ & $\begin{array}{l}\text { Study concept and design; } \\
\text { analysis and } \\
\text { interpretation; critical } \\
\text { revision of the manuscript } \\
\text { for important intellectual } \\
\text { content; and study } \\
\text { supervision }\end{array}$ \\
\hline $\begin{array}{l}\text { Dejan } \\
\text { Jakimovski, } \\
\text { MD, PhD }\end{array}$ & $\begin{array}{l}\text { Buffalo Neuroimaging } \\
\text { Analysis Center, Buffalo, } \\
\text { NY }\end{array}$ & $\begin{array}{l}\text { Study concept and design; } \\
\text { analysis and } \\
\text { interpretation; critical } \\
\text { revision of the manuscript } \\
\text { for important intellectual } \\
\text { content; and study } \\
\text { supervision }\end{array}$ \\
\hline $\begin{array}{l}\text { Jens Kuhle, } \\
\text { MD, PhD }\end{array}$ & $\begin{array}{l}\text { University of Basel, Basel, } \\
\text { Switzerland }\end{array}$ & $\begin{array}{l}\text { Study concept and design; } \\
\text { analysis and } \\
\text { interpretation; critical } \\
\text { revision of the manuscript } \\
\text { for important intellectual } \\
\text { content; and study } \\
\text { supervision }\end{array}$ \\
\hline $\begin{array}{l}\text { Jesper } \\
\text { Hagemeier, } \\
\text { PhD }\end{array}$ & $\begin{array}{l}\text { Buffalo Neuroimaging } \\
\text { Analysis Center, Buffalo, } \\
\text { NY }\end{array}$ & $\begin{array}{l}\text { Analysis and } \\
\text { interpretation and critical } \\
\text { revision of the manuscript } \\
\text { for important intellectual } \\
\text { content }\end{array}$ \\
\hline $\begin{array}{l}\text { Ozel Osman, } \\
\text { MD }\end{array}$ & $\begin{array}{l}\text { Buffalo Neuroimaging } \\
\text { Analysis Center, Buffalo, } \\
\text { NY }\end{array}$ & $\begin{array}{l}\text { Study concept and design; } \\
\text { analysis and } \\
\text { interpretation; and critical } \\
\text { revision of the manuscript } \\
\text { for important intellectual } \\
\text { content }\end{array}$ \\
\hline $\begin{array}{l}\text { Murali } \\
\text { Ramanathan, } \\
\text { PhD }\end{array}$ & $\begin{array}{l}\text { University at Buffalo, } \\
\text { Buffalo, NY }\end{array}$ & $\begin{array}{l}\text { Study concept and design; } \\
\text { analysis and } \\
\text { interpretation; and critical } \\
\text { revision of the manuscript } \\
\text { for important intellectual } \\
\text { content }\end{array}$ \\
\hline $\begin{array}{l}\text { Christian } \\
\text { Barro, MD, } \\
\text { PhD }\end{array}$ & $\begin{array}{l}\text { University of Basel, Basel, } \\
\text { Switzerland }\end{array}$ & $\begin{array}{l}\text { Analysis and } \\
\text { interpretation and critical } \\
\text { revision of the manuscript } \\
\text { for important intellectual } \\
\text { content }\end{array}$ \\
\hline
\end{tabular}

Appendix (continued)

\begin{tabular}{|c|c|c|}
\hline Name & Location & Contribution \\
\hline $\begin{array}{l}\text { Niels } \\
\text { Bergsland, } \\
\text { PhD }\end{array}$ & $\begin{array}{l}\text { Buffalo Neuroimaging } \\
\text { Analysis Center, Buffalo, } \\
\text { NY; IRCCS, Fondazione } \\
\text { Don Carlo Gnocchi, Milan, } \\
\text { Italy }\end{array}$ & $\begin{array}{l}\text { Analysis and } \\
\text { interpretation and critical } \\
\text { revision of the manuscript } \\
\text { for important intellectual } \\
\text { content }\end{array}$ \\
\hline $\begin{array}{l}\text { Davorka } \\
\text { Tomic, MD }\end{array}$ & $\begin{array}{l}\text { Novartis Pharma AG, } \\
\text { Basel, Switzerland }\end{array}$ & $\begin{array}{l}\text { Critical revision of the } \\
\text { manuscript for important } \\
\text { intellectual content }\end{array}$ \\
\hline $\begin{array}{l}\text { Harald } \\
\text { Kropshofer. } \\
\text { MD }\end{array}$ & $\begin{array}{l}\text { Novartis Pharma AG, } \\
\text { Basel, Switzerland }\end{array}$ & $\begin{array}{l}\text { Critical revision of the } \\
\text { manuscript for important } \\
\text { intellectual content }\end{array}$ \\
\hline $\begin{array}{l}\text { David } \\
\text { Leppert, MD }\end{array}$ & $\begin{array}{l}\text { Novartis Pharma AG, } \\
\text { Basel, Switzerland }\end{array}$ & $\begin{array}{l}\text { Critical revision of the } \\
\text { manuscript for important } \\
\text { intellectual content }\end{array}$ \\
\hline $\begin{array}{l}\text { Zuzanna } \\
\text { Michalak, } \\
\text { PhD }\end{array}$ & $\begin{array}{l}\text { University of Basel, Basel, } \\
\text { Switzerland }\end{array}$ & $\begin{array}{l}\text { Analysis and } \\
\text { interpretation } \\
\text { and critical revision of } \\
\text { the manuscript for } \\
\text { important intellectual } \\
\text { content }\end{array}$ \\
\hline $\begin{array}{l}\text { Norah } \\
\text { Lincoff, MD }\end{array}$ & $\begin{array}{l}\text { University of Basel, Basel, } \\
\text { Switzerland }\end{array}$ & $\begin{array}{l}\text { Analysis and } \\
\text { interpretation; critical } \\
\text { revision of the manuscript } \\
\text { for important intellectual } \\
\text { content }\end{array}$ \\
\hline $\begin{array}{l}\text { Michael G. } \\
\text { Dwyer, PhD }\end{array}$ & $\begin{array}{l}\text { Buffalo Neuroimaging } \\
\text { Analysis Center, Buffalo, } \\
\text { NY }\end{array}$ & $\begin{array}{l}\text { Analysis and } \\
\text { interpretation and critical } \\
\text { revision of the manuscript } \\
\text { for important intellectual } \\
\text { content }\end{array}$ \\
\hline $\begin{array}{l}\text { Ralph H.B. } \\
\text { Benedict, PhD }\end{array}$ & $\begin{array}{l}\text { University at Buffalo, } \\
\text { Buffalo, NY }\end{array}$ & $\begin{array}{l}\text { Study concept and design; } \\
\text { analysis and } \\
\text { interpretation; critical } \\
\text { revision of the manuscript } \\
\text { for important intellectual } \\
\text { content; and study } \\
\text { supervision }\end{array}$ \\
\hline $\begin{array}{l}\text { Bianca } \\
\text { Weinstock- } \\
\text { Guttman, MD }\end{array}$ & $\begin{array}{l}\text { University at Buffalo, } \\
\text { Buffalo, NY }\end{array}$ & $\begin{array}{l}\text { Study concept and design; } \\
\text { analysis and } \\
\text { interpretation; critical } \\
\text { revision of the manuscript } \\
\text { for important intellectual } \\
\text { content; and study } \\
\text { supervision }\end{array}$ \\
\hline $\begin{array}{l}\text { Robert } \\
\text { Zivadinov, } \\
\text { MD, PhD }\end{array}$ & $\begin{array}{l}\text { Buffalo Neuroimaging } \\
\text { Analysis Center, Buffalo, } \\
\text { NY }\end{array}$ & $\begin{array}{l}\text { Study concept and design; } \\
\text { analysis and } \\
\text { interpretation; critical } \\
\text { revision of the manuscript } \\
\text { for important intellectual } \\
\text { content; and study } \\
\text { supervision }\end{array}$ \\
\hline
\end{tabular}

\section{References}

1. De Stefano N, Giorgio A, Battaglini M, et al. Assessing brain atrophy rates in a large population of untreated multiple sclerosis subtypes. Neurology 2010;74:1868-1876.

2. Geurts JJ, Barkhof F. Grey matter pathology in multiple sclerosis. Lancet Neurol 2008;7:841-851.

3. Bergsland N, Horakova D, Dwyer MG, et al. Gray matter atrophy patterns in multiple sclerosis: a 10-year source-based morphometry study. Neuroimage Clin 2018;17: 444-451.

4. Filippi M, Preziosa P, Copetti M, et al. Gray matter damage predicts the accumulation of disability 13 years later in MS. Neurology 2013;81:1759-1767.

5. Zivadinov R, Jakimovski D, Gandhi S, et al. Clinical relevance of brain atrophy assessment in multiple sclerosis. Implications for its use in a clinical routine. Expert Rev Neurother 2016;16:777-793. 
6. Filippi M, Brück W, Chard D, et al. Association between pathological and MRI findings in multiple sclerosis. Lancet Neurol 2019;18:198-210.

7. Gordon-Lipkin E, Calabresi PA. Optical coherence tomography: a quantitative tool to measure neurodegeneration and facilitate testing of novel treatments for tissue protection in multiple sclerosis. J Neuroimmunol 2017;304:93-96.

8. Gupta S, Zivadinov R, Ramanathan M, Weinstock-Guttman B. Optical coherence tomography and neurodegeneration: are eyes the windows to the brain? Expert Rev Neurother 2016;16:765-775.

9. Wicki CA, Hanson JVM, Schippling S. Optical coherence tomography as a means to characterize visual pathway involvement in multiple sclerosis. Curr Opin Neurol 2018;31:662-668.

10. Petzold A, Balcer LJ, Calabresi PA, et al. Retinal layer segmentation in multiple sclerosis: a systematic review and meta-analysis. Lancet Neurol 2017;16:797-812.

11. Oberwahrenbrock T, Traber GL, Lukas S, et al. Multicenter reliability of semiautomatic retinal layer segmentation using OCT. Neurol Neuroimmunol Neuroinflamm 2018;5:e449. doi: 10.1212/NXI.0000000000000737.

12. Pietroboni AM, Dell'Arti L, Caprioli M, et al. The loss of macular ganglion cells begins from the early stages of disease and correlates with brain atrophy in multiple sclerosis patients. Mult Scler 2019;25:31-38.

13. Saidha S, Sotirchos ES, Oh J, et al. Relationships between retinal axonal and neuronal measures and global central nervous system pathology in multiple sclerosis. JAMA Neurol 2013;70:34-43.

14. Saidha S, Al-Louzi O, Ratchford JN, et al. Optical coherence tomography reflects brain atrophy in multiple sclerosis: a four-year study. Ann Neurol 2015;78:801-813.

15. Dörr J, Wernecke $\mathrm{KD}$, Bock $\mathrm{M}$, et al. Association of retinal and macular damage with brain atrophy in multiple sclerosis. PLoS One 2011;6:e18132.

16. Toledo J, Sepulcre J, Salinas-Alaman A, et al. Retinal nerve fiber layer atrophy is associated with physical and cognitive disability in multiple sclerosis. Mult Scler 2008; 14:906-912.

17. Garcia-Martin E, Rodriguez-Mena D, Herrero R, et al. Neuro-ophthalmologic evaluation, quality of life, and functional disability in patients with MS. Neurology 2013; 81:76-83.

18. Pisa M, Guerrieri S, Di Maggio G, et al. No evidence of disease activity is associated with reduced rate of axonal retinal atrophy in MS. Neurology 2017;89:2469-2475.

19. Sepulcre J, Murie-Fernandez M, Salinas-Alaman A, García-Layana A, Bejarano B, Villoslada P. Diagnostic accuracy of retinal abnormalities in predicting disease activity in MS. Neurology 2007;68:1488-1494.

20. Martinez-Lapiscina EH, Arnow S, Wilson JA, et al. Retinal thickness measured with optical coherence tomography and risk of disability worsening in multiple sclerosis: a cohort study. Lancet Neurol 2016;15:574-584.

21. Rothman A, Murphy OC, Fitzgerald KC, et al. Retinal measurements predict 10-year disability in multiple sclerosis. Ann Clin Transl Neurol 2019;6:222-232.

22. Housley WJ, Pitt D, Hafler DA. Biomarkers in multiple sclerosis. Clin Immunol 2015; 161:51-58.

23. Comabella M, Montalban X. Body fluid biomarkers in multiple sclerosis. Lancet Neurol 2014;13:113-126.

24. Gaiottino J, Norgren N, Dobson R, et al. Increased neurofilament light chain blood levels in neurodegenerative neurological diseases. PLoS One 2013;8:e75091.

25. Kuhle J, Barro C, Disanto G, et al. Serum neurofilament light chain in early relapsing remitting MS is increased and correlates with CSF levels and with MRI measures of disease severity. Mult Scler 2016;22:1550-1559.

26. Teunissen CE, Khalil M. Neurofilaments as biomarkers in multiple sclerosis. Mult Scler 2012;18:552-556.

27. Disanto G, Barro C, Benkert P, et al. Serum neurofilament light: a biomarker of neuronal damage in multiple sclerosis. Ann Neurol 2017;81:857-870.

28. Barro C, Benkert P, Disanto G, et al. Serum neurofilament as a predictor of disease worsening and brain and spinal cord atrophy in multiple sclerosis. Brain 2018;141: 2382-2391.
29. Kuhle J, Kropshofer H, Haering DA, et al. Blood neurofilament light chain as a biomarker of MS disease activity and treatment response. Neurology 2019;92: e1007-e1015.

30. Jakimovski D, Kuhle J, Ramanathan M, et al. Serum neurofilament light chain levels associations with gray matter pathology: a 5-year longitudinal study. Ann Clin Trans Neurol 2019;6:1757-1770.

31. Jakimovski D, Zivadinov R, Ramanthan M, et al. Serum neurofilament light chain level associations with clinical and cognitive performance in multiple sclerosis: a longitudinal retrospective 5-year study. Mult Scler 2019:1352458519881428.

32. Polman $\mathrm{CH}$, Reingold SC, Banwell B, et al. Diagnostic criteria for multiple sclerosis: 2010 revisions to the McDonald criteria. Ann Neurol 2011;69:292-302.

33. Jakimovski D, Gandhi S, Paunkoski I, et al. Hypertension and heart disease are associated with development of brain atrophy in multiple sclerosis: a 5-year longitudinal study. Eur J Neurol 2019;26:87-e8.

34. Jakimovski D, Ramanathan M, Weinstock-Guttman B, et al. Higher EBV response is associated with more severe gray matter and lesion pathology in relapsing multiple sclerosis patients: a case-controlled magnetization transfer ratio study. Mult Scle 2020;26:322-332.

35. Cruz-Herranz A, Balk LJ, Oberwahrenbrock T, et al. The APOSTEL recommendations for reporting quantitative optical coherence tomography studies. Neurology 2016;86:2303-2309.

36. Schippling S, Balk LJ, Costello F, et al. Quality control for retinal OCT in multiple sclerosis: validation of the OSCAR-IB criteria. Mult Scler 2015;21:163-170.

37. Tewarie P, Balk L, Costello F, et al. The OSCAR-IB consensus criteria for retinal OCT quality assessment. PLoS One 2012;7:e34823.

38. Kuhle J, Barro C, Andreasson U, et al. Comparison of three analytical platforms for quantification of the neurofilament light chain in blood samples: ELISA, electrochemiluminescence immunoassay and Simoa. Clin Chem Lab Med 2016;54:1655-1661.

39. Bsteh G, Berek K, Hegen H, et al. Serum neurofilament levels correlate with retina nerve fiber layer thinning in multiple sclerosis. Mult Scler 2019:1352458519882279.

40. Zimmermann H, Freing A, Kaufhold F, et al. Optic neuritis interferes with optical coherence tomography and magnetic resonance imaging correlations. Mult Scler 2013;19:443-450.

41. Fisher JB, Jacobs DA, Markowitz CE, et al. Relation of visual function to retinal nerve fiber layer thickness in multiple sclerosis. Ophthalmology 2006;113: 324-332.

42. Dogan U, Ulas F, Turkoglu SA, Ogun MN, Agca S. Eyes are mirror of the brain comparison of multiple sclerosis patients and healthy controls using OCT. Int J Neurosci 2019;129:848-855.

43. Gabilondo I, Martínez-Lapiscina EH, Martínez-Heras E, et al. Trans-synaptic axonal degeneration in the visual pathway in multiple sclerosis. Ann Neurol 2014;75: 98-107.

44. Al-Louzi OA, Bhargava P, Newsome SD, et al. Outer retinal changes following acute optic neuritis. Mult Scler 2016;22:362-372.

45. Behbehani R, Abu Al-Hassan A, Al-Salahat A, Sriraman D, Oakley JD, Alroughani R. Optical coherence tomography segmentation analysis in relapsing remitting versus progressive multiple sclerosis. PLoS One 2017;12:e172120.

46. Saidha S, Syc SB, Ibrahim MA, et al. Primary retinal pathology in multiple sclerosis as detected by optical coherence tomography. Brain 2011;134(pt 2):518-533.

47. Green AJ, McQuaid S, Hauser SL, Allen IV, Lyness R. Ocular pathology in multiple sclerosis: retinal atrophy and inflammation irrespective of disease duration. Brain 2010;133(pt 6):1591-1601.

48. Gelfand JM, Nolan R, Schwartz DM, Graves J, Green AJ. Microcystic macular oedema in multiple sclerosis is associated with disease severity. Brain 2012;135(pt 6): 1786-1793. 


\title{
Neurology \\ Neuroimmunology \& Neuroinflammation
}

\author{
Serum neurofilament light chain and optical coherence tomography measures in MS: A \\ longitudinal study \\ Eleonora Tavazzi, Dejan Jakimovski, Jens Kuhle, et al. \\ Neurol Neuroimmunol Neuroinflamm 2020;7; \\ DOI 10.1212/NXI.0000000000000737
}

This information is current as of May 18, 2020

\begin{abstract}
Updated Information \&
Services

References

Citations

Subspecialty Collections

Permissions \& Licensing

Reprints

including high resolution figures, can be found at: http://nn.neurology.org/content/7/4/e737.full.html

This article cites 46 articles, 1 of which you can access for free at: http://nn.neurology.org/content/7/4/e737.full.html\#\#ref-list-1

This article has been cited by 2 HighWire-hosted articles: http://nn.neurology.org/content/7/4/e737.full.html\#\#otherarticles

This article, along with others on similar topics, appears in the following collection(s):

Multiple sclerosis

http://nn.neurology.org//cgi/collection/multiple_sclerosis

Information about reproducing this article in parts (figures,tables) or in its entirety can be found online at:

http://nn.neurology.org/misc/about.xhtml\#permissions

Information about ordering reprints can be found online:

http://nn.neurology.org/misc/addir.xhtml\#reprintsus
\end{abstract}

Neurol Neuroimmunol Neuroinflamm is an official journal of the American Academy of Neurology.

Published since April 2014, it is an open-access, online-only, continuous publication journal. Copyright

Copyright (C) 2020 The Author(s). Published by Wolters Kluwer Health, Inc. on behalf of the American

Academy of Neurology.. All rights reserved. Online ISSN: 2332-7812.

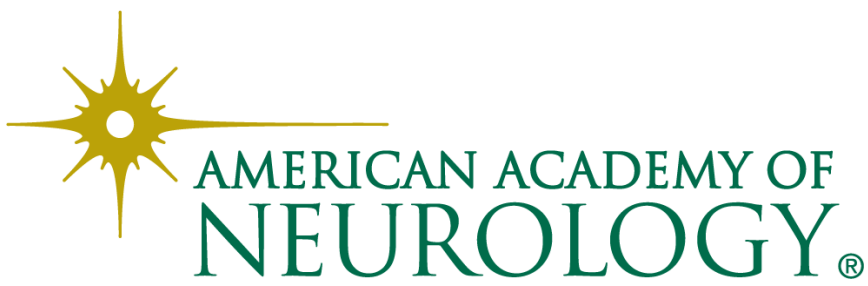

